\title{
Similitudes y diferencias entre dos tradiciones de Ricardo Palma y dos relatos del Inca Garcilaso de la Vega
}

\author{
Eduardo Huárag Álvarez \\ Pontificia Universidad Católica del Perú \\ ehuarag@pucp.pe
}

\section{Resumen}

El ensayo establece una comparación entre el relato del Inca Garcilaso sobre Aguirre, y el relato que Ricardo Palma denomina Las orejas del alcalde. Igualmente, se establece una comparación entre el relato sobre los melones y los nativos que creyeron haber sido delatados por una carta; y el relato de Palma que se titula Carta canta. Al comparar se podrá advertir las similitudes en la trama narrativa y la imagen de los personajes históricos; aunque también las notorias diferencias en el tratamiento del relato y el estilo discursivo. Se menciona un posible motivo por el que el escritor de las tradiciones no menciona al Inca Garcilaso siendo que fue el antecesor de la propuesta narrativa.

Palabras clave: Comentarios reales, tradiciones peruanas, relato, costumbrismo, texto, oralidad, procedimiento, narrador.

\section{Abstract}

The essay establishes a comparison between the story of the Inca Garcilaso about Aguirre, and the story that Ricardo Palma calls "The ears of the mayor." Likewise, a comparison is made between the account of the melons and the natives who believed they had been betrayed by a letter; and the story of Palma that are titled "Carta sings". When comparing it will be possible to notice the similarities in the narrative plot and the image of the historical personages; But also the notorious differences in the treatment of the story and the discursive style. It mentions why, probably, the writer of the traditions does not mention the Inca Garcilaso being that was the predecessor of the narrative proposal.

Keywords: Real comments, Peruvian traditions, story, costumbrismo, text, orality, procedure, narrator. 


\section{Eduardo Huárag Álvarez}

Profesor asociado del departamento de Humanidades de la Pontificia Universidad Católica del Perú. Ha sido profesor visitante en la Universidad de Burdeos y en la Universidad de Munich. Ha publicado libros de literatura latinoamericana relacionados con el pensamiento mítico. 
Nos parece pertinente analizar cómo es que un relato referido en un antiguo texto, como son los Comentarios reales del Inca Garcilaso de la Vega, luego aparece siendo recreado en las Tradiciones peruanas de Ricardo Palma. Ciertamente, lo primero que nos llama la atención son ciertas similitudes en el planteamiento argumental, hecho que podrá apreciar el lector. Pero queremos precisar también que -si bien el texto de Ricardo Palma tiene que haber tenido conocimiento de los Comentarios reales y de las historias que refiere el Inca- hay un procesamiento en el modo de narrar, en el estilo discursivo y en la importancia que le da Palma a la oralidad popular y que ello hace la diferencia entre uno y otro escritor.

Empezaremos dando una mirada a las secuencias narrativas de un texto que aparece en el capítulo XVIII de la segunda parte de los Comentarios reales (Lima, Universidad Inca Garcilaso de la Vega, 2007) y que lleva el título La venganza que Aguirre hizo de su afrenta y las diligencias del Corregidor por haberle a las manos, y cómo Aguirre se escapó En el mismo título de las Crónicas ya podemos advertir que el relato tiene como propósito dar a conocer la venganza de una afrenta, y luego las diligencias que realizó el Corregidor para capturar a Aguirre, revelando cómo es que el mencionado logró escapar. Compararemos el relato del Inca con la tradición que Palma titula Las orejas del alcalde. El sentido fundamental del relato desarrolla cómo fue que un alcalde se aprovechó de su poder para castigar a un soldado quien, considerando que se cometió una injusticia con él, pidió licencia para cobrarse venganza desorejando al alcalde. Pero veamos con más detalles lo que dice el relato del Inca Garcilaso para confirmar si estamos ante un texto que efectivamente es un antecedente argumental respecto del que realizó Ricardo Palma. 


\section{El Inca Garcilaso y Palma en un relato acerca de cómo resarcir el honor mancillado.}

1. En Comentarios reales del Inca Garcilaso, Aguirre se presenta como personaje que está buscando resarcir una afrenta:

(...) lo que había menester para su consuelo era buscar la muerte y darle priesa para que llegase aína. Y con esto se quedó en el Perú, y, cumplido el término del oficio del Licenciado Esquivel, dio en darse tras él como hombre desesperado, para matarle como quiera que pudiese, por vengar su afrenta (Garcilaso de la Vega, 2007: 926).

2. Cuando el Licenciado Esquivel se enteró que Aguirre le buscaba para matarlo: "dio en ausentarse y apartarse del ofendido, y no como quiera, sino trecientas y cuatrocientas leguas en medio, pareciéndole que viéndole ausente y tan lejos le olvidaría Aguirre" (Ibídem).

3. Pareciera que Aguirre no se amilana. Al contrario, encuentra un desafío la huida del Licenciado porque él no iba a desistir en su empeño: "Mas él cobraba tanto más ánimo cuanto más el Licenciado le huía, y le seguía por el rastro dondequiera que iba" (Ibídem).

4. Ahora obsérvese la persecución que realiza Aguirre, obsesionado con la idea de matar al Licenciado Esquivel. Se comenta que el Licenciado fue a la Ciudad de los Reyes: “(...) más dentro de quince días estaba Aguirre con él” (Ibídem).

5. Siempre con la idea de desmarcarse del acoso de Aguirre, Esquivel fue a la ciudad de Quito, que no estaba cerca: “(..) pero a poco de veinte días estaba Aguirre en ella (...)” (Ibid., p. 927). 
6. Preocupado, el Licenciado decidió volverse hacia el Cusco: “(...) por parecerle que habiendo en aquella ciudad un juez tan riguroso y justiciero, no se le atrevería Aguirre a hacer alguna cosa alguna contra él" (Ibídem).

7. El Inca Garcilaso, como para darle más autenticidad a su relato, comenta que un sobrino de su padre le habló al Licenciado Esquivel para aposentarse en su casa porque: “(...) sabiendo Aguirre que estoy con vuesa merced, no se atreverá a entrar en su casa" (Ibídem). Este dato es importante porque con ello el narrador quiere atestiguar que llegó a tener referencias del incidente a través de sus familiares. Por tanto, hay un fondo de veracidad en lo que está narrando.

8. Pero ni aún tal compañía impide que Aguirre cumpla con su propósito. De modo que un día se atreve a entrar en casa del Licenciado y luego de pasar por un corredor: “(...) le halló durmiendo sobre uno de ellos y le dio una puñalada en la sien derecha, que lo mató; y después le dio otras dos o tres por el cuerpo" (Ibídem).

A diferencia de lo que cuenta Palma en su tradición, aquí el personaje vengado mata a Esquivel con lo que se considera que ha logrado resarcir la afrenta y recuperado su honor. En el caso de la tradición de Palma el soldado vengador no piensa en matar al alcalde Esquivel, sino en darle un escarmiento para vengar el honor mancillado.

9. Cometido el homicidio, Aguirre estaba desesperado por buscar un lugar donde esconderse. Suplicaba: “iEscóndame, escóndanme!” (Ibid., p. 928). Para suerte de él, los familiares se avinieron a esconderlo. Le llevaban algo de comer mientras estaba en el refugio. 
10. Cuando el Corregidor supo del homicidio ordenó que nadie saliese de la ciudad sin permiso suyo. Pero la búsqueda no tuvo resultados positivos. Habían pasado cuarenta días y a sus protectores (Santillán y Cataño) se les ocurrió que era el momento de deshacerse de Aguirre porque de ser descubiertos como sus amigos serían sancionados drásticamente. Es importante decir que, en este episodio, el narrador dice respecto a los protectores que eran: “(...) caballeros muy nobles, que los conocí bien, y el uno dellos hallé en Sevilla cuando vine a España" (Ibid., p. 929). Con ello, el Inca refuerza la idea de que sus informantes fueron testigos excepcionales de lo que aconteció entre Aguirre y Esquivel, ganando veracidad.

11. Aguirre fue disfrazado de negro. Le raparon el cabello y la barba, y le pintaron el rostro. Iba a pie, delante de los amos, como solía ser el comportamiento de los esclavos. De ese modo, Aguirre logró burlar la vigilancia del Corregidor. Y quedó, en cierto modo, como un héroe que había huido luego de vengar una afrenta.

La tradición escrita por Ricardo Palma, empieza mencionando un detalle episódico que está respaldado por una historia de honor y venganza. Es decir, se trata también de un personaje que ha decidido resarcir su honor, de acosar a su agresor para hacerle sentir el acoso hasta el momento final de la venganza.

1. El relato empieza dando referencias de la Villa de Potosí, importante centro minero en la época. El alcalde de la villa era Diego de Esquivel, mujeriego y de malas costumbres. Esquivel andaba enamorado de una potosina que, por su parte, estaba más interesada en un soldado tucumano.

2. En el párrafo inicial el narrador, fiel a la recopilación de modos y costumbres arraigados en la oralidad, señala que por entonces se decía: "Pueblo minero, pueblo vicioso y pendenciero". 
(Palma, 1968: 123) El hecho anecdótico o episódico no tarda en presentarse. A contracorriente de las ordenanzas la gente se reunía para hacer apuesta en el juego de dado. Alguien hizo trampa y se armó el alboroto. Llegó el personal de vigilancia y detuvo a todos los parroquianos. Uno de los detenidos era el tucumano.

3. Según lo establecido, el transgresor de la ordenanza debía pagar 100 duros o recibir una docena de azotes. El soldado Cristóbal de Agüero inventa un motivo por el que estuvo en el centro de juegos. No quiere someterse al pago y advierte que no le corresponde recibir los azotes debido a su condición social: "(...) aunque soldado, soy hidalgo, y de solar conocido, y mi padre es todo un veinticuatro de Sevilla" (Ibid., p. 124).

4. Diego de Esquivel se burla del reclamo de Cristóbal de Agüero. El soldado hace una última advertencia: “(...) si se lleva adelante esa cobarde infamia, juro a Dios y a Santa María que he de cobrar venganza en sus orejas de alcalde" (Ibídem).

5. Cristóbal de Agüero recibirá los azotes que ordenó el alcalde. Luego de ello, el soldado dirá: "Contigo, Antúnez, no va nada (...) pero anuncia al alcalde que desde hoy las orejas que lleva me pertenecen, que se las presto por un año y que me las cuide como a mi mejor prenda". (Ibídem).

Si se establece la comparación entre ambos relatos, se trata de una afrenta, de un tema de honor. Hay un tal Diego de Esquivel como causante de la afrenta y un personaje (sea Aguirre o Cristóbal de Agüero) que ha sufrido un deshonor y que se ha propuesto vengar la afrenta.

6. Cristóbal de Agüero pide permiso para resarcir su honor. El capitán accede a su petición. Por esos días, Diego de Esquivel tuvo que trasladarse a Lima para realizar unos trámites. 
Mientras paseaba por la ciudad se sorprendió de que alguien se acercara para hablarle:

- ¿Mañana es el viaje, señor licenciado?

- ¿Le importa algo al muy impertinente?

- ¿Que si me importa? iY mucho! Como que tengo que cuidar esas orejas.

Y el embozado se perdió en una callejuela (Ibid., p. 126).

Nótese el efecto de los diálogos que inserta el narrador. No le basta con mencionar que el soldado tucumano persigue al causante de su deshonor, revive la escena para mostrar el desconcierto de Diego de Esquivel. Mientras en el relato del Inca Garcilaso se menciona que Aguirre seguía a su víctima para encontrar el momento de ajusticiarlo; aquí se trata de un vengador que se ha propuesto también el acoso pero no para matarlo, sino para cumplir con desorejarlo, como había ofrecido vengarse.

7. El acalde de Potosí viaja al Cusco y un día, al doblar una esquina se encuentra otra vez con el soldado tucumano: “-No se asuste, señor licenciado. Veo que esas orejas se conservan en su sitio y huélgome de ello" (Ibídem).

El acoso era obsesivo. Se le presentaba en el momento menos esperado para hacerle saber que lo seguía, que no podría escapar a su venganza. Es un acoso torturante, de innegable repercusión psicológica. Es decir, el acoso es parte de la venganza.

8. Diego de Esquivel decide ir a Guamanga. Estaba en una posada cuando, al anochecer, escuchó que llamaban a la puerta: 
-¿Quién? - preguntó el golilla.

-iAlabado sea el Santísimo! -contestó el de fuera.

-Por siempre alabado, amén -y se dirigió don Diego a abrir la puerta (Ibídem).

Esquivel se quedó petrificado al ver que el soldado que hizo azotar estaba nuevamente ante él. No había logrado liberarse del asedio. Y él, en un tono de sorna, dirá: "Calma, señor licenciado. ¿Esas orejas no sufren deterioro? Pues entonces, hasta más ver" (Ibídem).

La situación había llegado a tal grado de exasperación, dice el narrador, que: "El terror y el remordimiento hicieron enmudecer a don Diego" (Ibídem).

9. Cuando Esquivel se traslada a Lima, el asedio se convierte en exasperante, vergonzoso: "No había medio de esquivarlo. En el templo y en el paseo era el pegote de su sombra, su pesadilla eterna" (Ibídem). Hasta que llega el año de los latigazos de la deshonra y a pesar de que Esquivel había asegurado la puerta de su posada, el soldado de la venganza entra a su aposento:

(...) dos brazos nervudos sujetaron a Esquivel, una mordaza ahogó sus gritos y fuertes cuerdas ligaron su cuerpo al sillón.

El hidalgo de Potosí estaba delante, y un agudo puñal relucía en sus manos.

-Señor alcalde mayor -le dijo-. Hoy vence el año y vengo por mi honra. 
Y con salvaje serenidad rebanó las orejas del infeliz licenciado (Ibid., p. 126-127).

La venganza se había consumado. El acoso terminó con el corte de las orejas del alcalde. Obsérvese que, a diferencia del relato de Aguirre, resarcir el honor no significa necesariamente la muerte del agraviante. En el caso de Palma se trata de someter a un castigo que puede ser relativamente menos trágico. Lo que sucede es que el efecto va por el lado de la vergüenza pública. El corte de ambas orejas sería una vergüenza y él no podría pasearse por la ciudad bajo el riesgo de ser calificado como "desorejado". Y esa era una venganza, entonces, con efectos sociales.

10. Si el Inca concluye el relato de Aguirre narrando el episodio del disfraz para huir de la persecución del Corregidor; en Palma, el soldado vengador recurre al rey Carlos V para exponerle su caso de deshonor. El rey le concede el perdón y le da la categoría de capitán para que siga en actividad militar.

El recuento de ambos relatos nos ha permitido observar en qué aspectos coinciden y en qué otros Palma se diferencia del célebre cronista. Palma, en verdad, utiliza la historia como fuente argumental, pero recrea la historia de tal modo que la hace diferente en la configuración de los personajes. Si el móvil es semejante en tanto que el honor es un motivo clave de venganza, en lo que se diferencian es en el modo de resarcir la afrenta.

En ambos hay un acoso al autoritario e injusto; en Palma es importante revivir las escenas para dar al relato mayor autenticidad y fuerza evocadora. De ese modo Palma maneja con acierto el suspenso. No queremos decir que Palma sea mejor narrador. En realidad cada narrador tiene su estilo y Palma es fiel a su modo de contar una historia, de darle ese tono, entre el suspenso y el humor, como no lo hicieron otros costumbristas. 


\section{La palabra delatora en un relato referido por el Inca Garcilaso y Ricardo Palma}

El segundo relato sobre el que nos interesa reflexionar es el que inserta el Inca Garcilaso en el capítulo XXIX de sus Comentarios reales (Garcilaso de la Vega, 2007: 848) y que titula "De las hortalizas y yerbas, y de la grandeza dellas". Palma, a su vez, presenta el relato como Carta canta. Es necesario consignar que tanto el Inca Garcilaso como Ricardo Palma refieren la fuente del relato que no sería otro que el Padre José de Acosta y que, como anota el Inca Garcilaso, hace la mención en el Libro cuarto, capítulo diez y nueve.

En el caso de Palma también hace la mención al religioso: "Leyendo anoche al jesuita Acosta que como ustedes saben escribió largo y menudo sobre los sucesos de la conquista" (Palma, 1968: 147). Ello explica que lo señalado por el jesuita historiador haya servido como fuente de información a la vez que motivo de inspiración que cada uno, en su estilo y modo, ha terminado narrando el episodio anecdótico.

Pero veamos primero el texto del Inca Garcilaso. Las secuencias narrativas que presenta en el capítulo XIX son:

1. En el primer y el segundo párrafo, el cronista hace referencia a las legumbres y yerbas que trajeron los españoles al Perú, que aquí no se conocían: “(...) lechugas, escarolas, rábanos, coles, nabos, ajos, cebollas, berenjenas, espinacas, acelgas, yerbabuena, culantro, perejil, ni cardos hortenses ni campestres, ni espárragos". (Garcilaso de la Vega, 2007: 848). Pero así como ofrece esta referencia, advierte que muchas de las yerbas y hortalizas dieron mejores cosechas que en España. Y como para autenticar la veracidad de su afirmación señala que cuando pasaba por Cañete, camino a España, un tal Garci Vázquez que había sido empleado de su padre le invitó a cenar y le dijo: 
Comed de ese pan, que acudió a más de trescientas hanegas, porque llevéis que contar a España. Yo me hice admirado de la abundancia, porque la ordinaria, que yo antes había visto, no era tanta ni con mucho, y me dijo el Garcí Vásquez: No se os haga duro de creerlo, porque os digo verdad, como cristiano, que sembré dos hanegas y media de trigo y tengo encerradas seiscientas y ochenta, y se me perdieron otras tantas, por no tener con quién las coger (Ibid., p. 849).

2. Se menciona también que en Arica, en el valle de Cuzapa:

(...) había un rábano de tan extraña grandeza que a la sombra de sus hojas estaban atados cinco caballos (...) El rábano era tan grueso que apenas lo ceñía un hombre con los brazos, y tan tierno, que después se llevó a la posada de Don García y comieron muchos dél (Ibídem).

3. Luego el Inca hace mención al Padre Maestro Acosta para reconfirmar que los españoles trajeron legumbres y que la tierra es fértil en la producción, por ejemplo de melones. Y luego agrega: “(...) los primeros melones que en la comarca de los Reyes se dieron causaron un cuento gracioso, será bien que lo pongamos aquí, donde se verá la simplicidad que los indios en su antigüedad tenían”. (Ibid., p. 851).

4. En el relato del Inca se menciona que:

(...) un vecino de aquella ciudad (Lima), conquistador de los primeros, llamado Antonio Solar, hombre noble, tenía una heredad en Pachacámac, a cuatro leguas de los Reyes, con un capataz español que miraba por su hacienda, el cual envió a su amo diez melones que llevaron dos indios a cuestas, según la costumbres dellos, con una carta. A la partida le dijo el capataz: "No comáis ningún melón déstos, porque si lo coméis lo ha de decir esta carta (Ibídem). 
Nótese que este relato sigue los procedimientos narrativos que ha seguido Valdimir Propp (1985). De modo que esta advertencia del capataz equivale a lo que se entendería como Prohibición o Advertencia, en la terminología de Propp.

5. Encomendada la misión, los indios fueron hacia la Ciudad de los Reyes. En el camino el apetito y la curiosidad pudo más y uno de ellos dijo:

No sabríamos a qué sabe esta fruta de la tierra de nuestro amo. El otro dijo: No, porque si comemos alguno, lo dirá esta carta, que así nos lo dijo el capataz.

Replicó el primero: Buen remedio; echemos la carta detrás de aquel paredón, y como no nos vea comer, no podrá decir nada (Ibídem).

Y fue así como comieron con tranquilidad el melón que les apetecía. Este episodio se entenderá, en el proceso narrativo funcionalista de Propp como transgresión. Es decir, los personajes no cumplieron con la advertencia y se convirtieron en transgresores.

6. Más adelante, quien llevaba cinco melones le dijo al que llevaba cuatro:

No vamos acertados, conviene que emparejemos las cargas, porque si vos lleváis cuatro y yo cinco, sospecharán que nos hemos comido el que falta. Dijo el compañero: "Muy bien decís" Y así, por encubrir un delito, hicieron otro mayor, que se comieron otro melón (Ibídem).

Desde el punto de vista narrativo, al comerse el otro melón, lo que han hecho es ahondar su condición de transgresores. Pensaban que debían equiparar la cantidad de melones para 
mayor credibilidad y que no se supiera de la apropiación que hicieron.

7. En los relatos populares, luego de la transgresión viene la revelación de la falta cometida y lo que Propp entiende como Sanción. Y eso es lo que va a suceder cuando el amo terminó de leer la carta: "¿Qué son de dos melones que falta aquí? Ellos a una respondieron: "Señor, no nos dieron más de ocho". Dijo Antonio Solar; "¿Por qué mentís vosotros, que esta carta dice que os dieron diez y que os comisteis los dos?" (Ibídem).

Ante la evidencia los indios no supieron qué decir. Finalmente, señala el narrador que por tal motivo se les llamaba Viracocha, como los dioses, "(...) pues alcanzaban tan grandes secretos" (Ibídem).

Aunque no lo dice de modo explícito, queda claro que el amo descubrió la verdad debido a lo que se decía en la carta. Y podemos decir también que se pone en evidencia la mentalidad mágico religiosa de los nativos que, no entendiendo el sentido de la palabra escrita, le atribuyen poderes mágico-religiosos, tanto que suponen que habiendo tenido la facultad de descubrir la verdad los españoles tenían la categoría de Viracochas.

En el caso de la tradición "Carta canta" de Ricardo Palma, el narrador inicia su relato mencionando el sentido o la trascendencia de la palabra escrita. Palma andaba tan pendiente del significado de las palabras en la cultura oral por lo que dice:

(...) hoy mismo, para poner remate a una disputa, solemos echar mano al bolsillo y sacar una misiva diciendo: -Pues, señor, carta canta (...) Lo que es la gente ultracriolla no hace 
rezar ni cantar a las cartas, y se limita a decir: papelito manda. (Palma, 1968: 147).

1. Palma hace referencia a su fuente para efectos de su relato y nombra: “(...) al jesuita Acosta que, como ustedes saben, escribió largo y menudo sobre los sucesos de la conquista" (Ibídem). Luego, iniciando ya el relato, menciona, en su estilo discursivo de tono popular:

Creo haber contado antes de ahora (...) que cuando los conquistadores se apoderaron del Perú no eran en él conocidos el trigo, el arroz, la cebada, la caña de azúcar, lechugas, rábanos, coles, espárragos, ajos, cebollas, berenjenas, hierbabuena, garbanzos, lentejas, habas (Ibídem).

2. También Palma destaca que: "Algunas de las nuevas semillas dieron en el Perú más abundante y mejor fruto que en España" (Ibídem).

Adviértase que Palma está construyendo su relato siguiendo las mismas secuencias narrativas que el Inca Garcilaso. Inclusive, encontramos la referencia al rábano gigante que se cosechó en Arica: "Se produjo un rábano tan colosal, que no alcanzara un hombre a rodearlo con los brazos, y que don García Hurtado de Mendoza (...) se quedó extático y con un palmo de boca abierta mirando tal maravilla" (Ibídem).

3. Luego, más en concreto, refiere que Antonio Solar, uno de los que llegó con los conquistadores, obtuvo un lote en Lima para su casa y: “(...) doscientas fanegadas de feraz terreno en los valles de Supe y Barranca, y cincuenta mitayos o indios para su servicio" (Ibídem). 
Adviértase que ahora la ubicación del predio rústico del señor Antonio Solar ha cambiado. Para el Inca Garcilaso estaba en Pachacamac (sur de Lima) y para Palma en Barranca (norte de Lima).

4. La tradición de Palma menciona que llegó el momento en que el melonar dio su cosecha en esos predios de Barranca. También se alude a que el mayordomo escogió diez melones y los acondicionó en dos cajas y envió a los indios a que los lleven al amo. Se adjuntaba a los melones una carta. Nótese aquí que no hay advertencia a los indios.

5. En el trayecto, los indios desearon comer los melones. Uno de ellos dijo: "¿Sabes, hermano (...) que he dado con la manera de que podamos comer sin que se descubra el caso? Escondamos la carta detrás de la tapia, que no viéndonos ella comer no podrá denunciarnos" (Ibid., p. 148).

Si en el razonamiento del Inca Garcilaso las propiedades de la escritura se relacionaban con la facultad de que los usuarios sepan hasta lo que no se ve, explicación propia del pensamiento mágico-religioso (por lo que creyeron que los españoles eran como los dioses Viracocha); en el caso de Palma se dice que: "La sencilla ignorancia de los indios atribuía a la escritura un prestigio diabólico y maravilloso” (Ibídem).

6. Los mitayos o indios comieron entonces un melón, pero casi al llegar a Lima uno de ellos dijo: "Hermano, vamos errados. Conviene que igualemos las cargas; porque si tú llevas cuatro y yo cinco, nacerá alguna sospecha en el amo" (Ibídem). Y comieron el segundo melón.

7. Cuando llegan a casa del amo le entregaron la carta y don Antonio, luego de revisar la carga dijo: "iCómo se entiende, ladronzuelos(...) el mayordomo me manda diez melones y aquí 
faltan dos" (Ibídem). Se había descubierto la apropiación de melones de parte de los indios. Los indios recibieron el castigo correspondiente y luego reflexionaron:

¿Lo ves, hermano? iCarta canta!”. Alcanzó a oírlos don Antonio, y les gritó: "Sí, bribonazos, y cuidado con otra, que ya saben ustedes que carta canta." (Ibídem). Según Palma, “(...) la frase se generalizó y pasó el mar. (Ibídem).

Se puede apreciar que en ambos casos hay un esfuerzo por recrear el incidente anecdótico. Tal recreación no es tan libre puesto que muchos de los aspectos secuenciales del texto de Acosta aparecen en ambos escritores: el Inca Garcilaso y Palma. Y aunque otras veces Palma se interesa por ahondar aún más su recreación en los rasgos que caracterizan a los personajes, no lo ha hecho en este caso porque, como se sabe, el mundo andino no es un tema con el que se encuentre tan familiarizado.

\section{La omisión del antecesor}

En los relatos mencionados y en casi todas sus tradiciones, la mirada de Palma sobre el indio es epidérmica. Es que a Palma le interesa más el hecho episódico, no la caracterización ni la mirada al interior del indio o el trasfondo de sus creencias. Además, el escritor romántico parece sentirse mejor en la recreación de acontecimientos y personajes del ámbito limeño, de esos tiempos virreinales en que los españoles y criollos andaban detrás de aventuras de honor o de otra índole. El indio que presenta el Padre José de Acosta es casi el mismo que muestra el Inca Garcilaso, con el agregado de que, para el Inca, los nativos parecen atribuir a la palabra una condición mágico-religiosa. Prevalece en el Inca su afán de buscar 
explicaciones antropológicas. En el caso de Palma, prevalece su afán de captar y trasmitir la cultura oral.

Antes de concluir el presente ensayo y, por lo que hemos podido observar, las tradiciones de Ricardo Palma están endeudadas con los relatos del Inca Garcilaso de la Vega por el planteamiento de la trama y la concepción de los personajes. Surge entonces la pregunta: ¿Por qué omitió Ricardo Palma la fuente que le sirvió de inspiración? No es el primer caso en el que un escritor de relatos toma como referencia crónicas o episodios de historiadores. El que ficcionaliza a partir de una propuesta temática, como sucedió con La guerra del fin del mundo, de Mario Vargas Llosa, basada en la crónica de Euclides da Cunha, tiene la obligación de ofrecer la referencia. La valoración a su obra de ficción sabrá distinguir cuál es la diferencia en el tratamiento, hecho en el que Ricardo Palma se diferencia, ciertamente, del Inca Garcilaso.

Este tipo de estudio, es decir, la posible vinculación y diferencia entre el texto histórico y el relato ficcional fue advertido también por Merlin Compton. El investigador mencionado se dedica a establecer la vinculación de tradiciones que tienen referencias de hechos históricos o crónicas de historiadores. En su criterio, hay: “(...) una gama que va desde las que siguen la fuente histórica fielmente hasta las que emplean la historia sólo como punto de partida para la creación de obras de arte" (Compton, 2000: 111).

Entonces, ¿por qué Palma no mencionó al Inca? La pregunta abre dudas, desconciertos y conjeturas. Me aventuro a señalar dos reflexiones: a) Palma prefirió omitir al Inca Garcilaso por el injustificado temor de que pudiera opacar su imagen de escritor de relatos literarios; b) Palma creyó innecesario hacer el deslinde entre historia y ficción narrativa y consideró que sea el 
lector quien vea la diferencia entre la información histórica o el relato histórico y la ficción narrativa.

El problema se complica para el lector porque el Inca Garcilaso tampoco se reduce a ser un cronista de hechos objetivos, históricos, sino que se permite insertar relatos en los que se aprecia su estilo de narrador. Lo que queda claro es que Palma quiso que se conociera la historia de los hechos pasados de manera amena y destacó las costumbres y creencias de la cultura popular. Un aspecto que en las últimas décadas se empieza a encontrar relevante.

El tiempo puso las cosas en su lugar y ambos, el Inca Garcilaso y Palma, tienen méritos que los lectores y analistas saben valorar, cada uno con el aporte a la cultura nacional.

\section{Bibliografía}

Compton, M. (2000). La historicidad de las Tradiciones Peruanas de Ricardo Palma. Lima, editorial de la Biblioteca Nacional del Perú.

De Acosta, J. (2008). Historia natural y moral de las Indias. Madrid: Consejo Superior de Investigaciones Científicas.

Garcilaso de la Vega, I. (2007). Comentarios reales. Lima: Universidad Inca Garcilaso de la Vega.

Palma, R. (1968). Tradiciones peruanas completas. Madrid: Ediciones Aguilar.

Propp, V. (1985). Morfología del cuento. Madrid: Ediciones Fundamentos. 